in animals has shown that allogeneic bone marrow transplantation can alter the course of immune mediated disorders such as lupus nephritis and diabetes mellitus

It is interesting to speculate that allogeneic bone marrow transplantation may have a therapeutic role in the management of serious intractable autoimmune disorders.

S N JOWITT J A LIU YIN

Department of Haematology,

Manchester Royal Infirmar

Manchester M139WL

1 Eedy DJ, Burrows D, Bridges JM, Jones FGC: Clearance of severe psoriasis after allogenic bone marrow transplantation. BrMed F 1990;300:908. (7 April.)

2 Ikehara S, Nakamura T, Sekita K, et al. Treatment of systemic and organ-specific autoimmune disease in mice by allogeneic bone marrow transplantation.Prog C.lin Biol Res 1987;229:131. 46.

3 Shiraki $M$, Fujiwara $M$, Kano K. Rectification of immunological abnormalities and lupus nephritis by transfer of bone marrow cells. Ann NY Acad Sci 1983;420:309-14.

\section{Enalapril and metoprolol in diabetic nephropathy}

SIR,-Dr S Björck and colleagues conclude that enalapril reduces proteinuria in patients with diabetic nephropathy by a specific action that is independent of its effect on systemic blood pressure, and they assume that the observed antiproteinuric effect of enalapril may be beneficial to the kidneys.' This promising finding appears to strengthen previous suggestions for using angiotensin converting enzyme inhibitors as the treatment of choice in diabetic hypertension. Nevertheless, their results should be interpreted with some caution.

Firstly, the reductions in blood pressure achieved by enalapril and metoprolol at the doses applied (with or without frusemide or hydralazine, or both) were not equal in the study. For example, the supine systolic blood pressure decreased from the baseline value by a mean of $22 \mathrm{~mm} \mathrm{Hg}$ after treatment with enalapril for eight weeks and by only $13 \mathrm{~mm} \mathrm{Hg}$ with metoprolol. The possibility cannot be excluded that the greater reduction in systemic blood pressure observed in the patients treated with enalapril partly caused the greater antiproteinuric effect of the drug.

Secondly, the treatment with enalapril over eight weeks caused a non-significant, but obvious and continuous, increase in serum creatinine concentration by $7 \cdot 5 \%$, whereas the concentration remained unchanged in the patients treated with metoprolol. Elevated serum creatinine concentration was a sign of worsening kidney function in these patients, even though the authors did not evaluate the glomerular filtration rate after treatment. Deterioration of renal function has been reported in some patients after the use of angiotensin converting enzyme inhibitors. Enalapril may contribute to decline in renal function in certain vulnerable patients, ${ }^{2}$ especially those receiving high doses of loop diuretics.

Thirdly, the finding that treatment with enalapril over only eight weeks increased serum potassium concentration by $9 \%$ seems clinically important because such an increase could be life threatening. Regular monitoring of serum potassium concentration might be necessary during the use of angiotensin converting enzyme inhibitors.

If the ultimate aim of antihypertensive treatment is to preserve kidney function in diabetic patients with advanced nephropathy rather than only reducing the amount of proteinuria, the comprehensive results by Björck and colleagues seem to reflect a potentially harmful effect of angiotensin converting enzyme inhibitors in these patients. The benefits of long term use of angiotensin converting enzyme inhibitors compared with other antihypertensive drugs in hypertensive diabetic

patients with reduced kidney function are still not clear.

T BABA T KODAMA K TAKEBE

Third Department of Internal Medicine,

Hirosaki University School of Medicine.

Japan

I Björck S, Mulec H, Johnsen SA, Nyberg (i, Auretl $M$ Contrasting effects of enalapril and metoprolol on proteinuria in diabetic nephropathv. Br.Med f 1990;300:904-7. (7 April.) 2 Inman WHW, Rawson NSB, Witton LV, Pearce GL, Speirs CJ. Postmarketing surveillance of enalapril. I: Results of prePostmarketing surveillance of enalapril. I: Results
scription event monitoring. Br Med $\mathcal{f}$ 1988;297:826-9.

Speirs CJ, Dollery CT, Inman WH, Rawson NSB, Wilton LV peirs CJ, Dollery CT, Inman WH, Rawson NSB, Wilton LV.
Postmarketing surveillance of enalapril. II: Investigation of potential role of enalapril in deaths with renal failure. Br.Med $\mathcal{f}$ 1988;297:830-2

+ Sawicki PT, Mühlhauser I, Baba T, Berger M. Do angiotensin converting enzyme inhibitors represent a progress in hypertension care in diabetes mellitus? Diabetologia 1990;33:121-4.

SIR,-At the end of the study by Dr S Björck and colleagues patients receiving metoprolol and those receiving enalapril had similar mean arterial pressures (102 (SD 11) $\mathrm{mm} \mathrm{Hg} v 99$ (SD 7) $\mathrm{mm} \mathrm{Hg}$ ), but there was a considerable, albeit not significant, difference between the groups at the start of the study $(109$ (SD 10) $\mathrm{mm} \mathrm{Hg}$ $v 114(\mathrm{SD} 8) \mathrm{mm} \mathrm{Hg}, \mathrm{p}=0 \cdot 09)$. Consequently the reduction in mean arterial pressure in the enalapril group was more than twice that in the metoprolol group ( $15 \mathrm{~mm} \mathrm{Hg} v 7 \mathrm{~mm} \mathrm{Hg}$ ).

If the decrement in blood pressure (as well as the final blood pressure) is important in reducing proteinuria then the greater antiproteinuric effects of enalapril can be explained in terms of its antihypertensive effect. Furthermore, metoprolol produced a significant reduction in systolic blood pressure only at eight weeks and did not significantly reduce diastolic pressure, unlike enalapril which significantly reduced systolic and diastolic blood pressure at both four and eight weeks. This suggests that metoprolol may not have been as effective an antihypertensive agent as enalapril, particularly during the first four weeks.

Finally, because of the significant effects on proteinuria of dietary protein restriction in diabetic nephropathy, it is important to establish that dietary protein intake did not change during the study.

K J HARDY

North Staffordshire Royal Infirmary,

Stoke-on-Trent,

Staffordshire ST $44 \mathrm{LN}$

1 Biörck S, Mulec H, Johnsen SA, Nyberg G, Aurell M. Contrast ing effects of enalapril and metoprolol on proteinuria in
diabetic nephropathy. Br.Med f 1990;300:904-7. (7 April.)

AUTHOR'S REPLY, - As both commentators point out, the baseline blood pressure was higher, although not significantly, in the patients given metropolol. This is an effect of chance in the randomisation procedure. Our goal was to achieve similar blood pressure during treatment with both drug regimens and I believe we succeeded fairly well. Unfortunately, the wrong picture was printed as figure 1 but this error has now been corrected.'

Using similar blood pressure control the degree of both albuminuria and proteinuria in the patients given enalapril was less than half of that in the patients given metoprolol. We concluded that this was caused by a pressure-independent antiproteinuric effect of enalapril. Many of the patients still show a reduction in proteinuria after up to 18 months' observation.

Dr Hardy asks about protein intake - there was no change in diet or in protein intake as measured by urinary excretion of nitrogen. Dr Baba and colleagues point out that the serum creatinine concentration rose in the patients given enalapril but not in those given metoprolol. This might reflect haemodynamic changes which led to the reduction in proteinuria. This is probably an early adaptation to the angiotensin converting enzyme inhibitor because, during the next four months, the serum creatinine concentration increased by 11 (SE 9) $\mu \mathrm{mol} / \mathrm{l}$ in the patients given metoprolol and decreased 3 (SE 5) $\mu \mathrm{mol} / 1$ in those given enalapril.

It is too early to conclude whether enalapril treatment protects kidney function more than metoprolol treatment in the long term. Earlier uncontrolled data that remain to be proved show that angiotensin converting enzyme inhibitors might have a specific renal protective effect. Hyperkalaemia is a complication of angiotensin converting enzyme inhibitor treatment in all patients with renal failure, thus frusemide is the logical first choice in these patients to reduce the risk of hyperkalaemia. The overall reported experience with angiotensin converting enzyme inhibitors in diabetic patients, now covering more than 450 patients, is that the treatment is effective, safe, and well tolerated. ${ }^{3}$ The lack of side effects on lipids and metabolic control and a lesser degree of orthostatic hypotension are advantages with these new drugs.

Department of Nephrology

STAFFAN BJÖRCK

Sahlgrenska Hospital,

University of Götebor

S-413 45 Götehorg

Sweden

I Björck S, Mulec H, Johnsen SA, Nyberg G, Aurell M. Contrasting effects of enalapril and metoprolol on proteinuria in diabetic nephropathy [Correction]. Br Med f 1990;300:1170. (5 May.) Björck S, Nyberg G, Mulec H, Granérus G, Herlitz. H, Aurell M Beneficial effects of angiotensin converting enzyme inhibition on renal function in patients with diabetic nephropathy. BrMed f 1986;293:471-4

3 Bjorck S. The renin angiotensin system in diabetes mellitus, physiological and therapeutic study. Scand $\mathcal{J}$ Urol Nephrol 1990; 126 (suppl) $): 1-51$.

\section{Node negative breast cancer}

SIR, - We accept the comment by Professor R W Blamey and colleagues that the Nottingham prognostic index can define subgroups of patients with operable breast cancer who have differen prognoses and that these findings have been validated in Nottingham. ' This index has, however, not achieved widespread acceptance. It is based on a combination of lymph node stage and size and histological grade of tumour. Lymph node stage in this instance is based on a triple node biopsy (that is, biopsy of a lower axillary node, an apical axillary node, and a node from the internal mammary chain) which is not a common procedure. In addition, while both the Guy's and Nottingham breast units are extremely fortunate to have histopathologists with special skills in classifying breast tumours, tumour grade can be highly observer dependent. $^{2}$

Our review was confined to patients with node negative breast cancer. ${ }^{2}$ Knowledge of the state of the patients' axillary nodes clearly depends on adequate dissection. Dissection was routine practice when modified radical mastectomy was the treatment of choice for operable breast cancer. But as Drs Leslie and Maher have pointed out, since the advent of breast conservation techniques, many surgeons no longer dissect the axilla. ${ }^{+} \mathrm{We}$ feel strongly that, particularly in younger women, knowledge of lymph node state is important to help determine whether adjuvant chemotherapy is indicated.

For patients who have no affected nodes on full axillary dissection it is clearly possible to define prognostic subgroups. Using a combination of tumour size and either histological grade or Sphase fraction measured by flow cytometry three groups of patients with relapse-free survival rates of $95 \%, 78 \%$, and $52 \%$ over five years can be identified. ${ }^{6}$ We are currently validating this in a larger group of patients. Both the Guy's and Nottingham prognostic indices can potentially 
help in the selection of patients for adjuvant therapy. The choice of index will depend on the surgical staging procedure adopted by a particular centre.

Imperial Cancer Research Fund Clinical Oncolngy Unit,

Guy's Hospital, London SE1 9RT

1 Blamey RW, Elston CW, Ellis IO, Morgan DAL, Maybittle JL. Node negative breast cancer. Br Med f 1990;300:1137. (28 April.)

2 Delides GS, Garas G, Georgouli G, et al. Interlaboratory variation in the grading of breast cancer. Arch Pathol Lab Med 1982;106:126-8.

3 O'Reilly SM, Richards MA. Node negative breast cancer. BrMed f 1989;300:346-8. (10 February.)

4 Leslie MD, Maher EJ. Node negative breast cancer. Br Med $\mathcal{f}$ 1990;300:749. (17 March

5 Early Breast Cancer Trialists' Group. Effect of adjuvant tamoxifen and of cytotoxic therapy on mortality in early breast cancer. N Engl f Med 1988;319:1681-92.

6 O'Reilly SM, Camplejohn RS, Barnes DM, Millis RR, Ruben RD, Richards MA. Node negative breast cancer: prognostic subgroups defined by tumour size and flow cytometry. $f$ Clin Oncol (in press).

\section{Pelvic inflammatory disease}

SIR, - In his recent editorial Mr J Malcolm Pearce highlights the often inadequate diagnosis and treatment of women with pelvic inflammatory disease.' My own study, which was based on a questionnaire sent to individual practitioners requesting details of their management of pelvic inflammatory disease, illustrates the extent of the problem in general practice.

Of 112 general practitioners returning their questionnaires, $94(84 \%)$ provided a combination of antibiotics, $28(25 \%)$ provided antichlamydial treatment, and only four provided combination treatment against Chlamydia trachomatis and Neisseria gonorrhoeae. In total 44 doctors $(40 \%)$ considered investigating or referring male consorts. Only two doctors remarked that they routinely refer for diagnosis all patients with a first attack of pelvic inflammatory disease.

Although optimum management may require admission and diagnostic laparoscopy, this may be impracticable. It might be helpful, therefore, for gynaecologists to develop with genitourinary physicians and general practitioners clear guidelines on treatment and referral to hospital. The evidence so far suggests that the management of pelvic inflammatory disease could be improved greatly.

ANDREW J EYNON-LEWIS

Dartmouth, Devon TQ6 9HT

1 Pearce JM. Pelvic inflammatory disease. $\mathrm{Br} M e d$ f 1990;300: 1090-1. (28 April.)

2 Eynon-Lewis AJ. Audit of the management of pelvic inflammatory disease in general practice. $\mathcal{F} R$ Coll Gen Prac 1988:38:492-3

SIR, - The editorial by Mr J M Pearce' is welcomed by most of us who practise genitourinary medicine, and we hope that it will improve referrals to our specialty. But Mr Pearce fails to emphasise the cost effectiveness of efficient treatment-in terms of misery in patients, morbidity, and precious NHS funds. The pennies spent on antibiotics cannot be compared with the thousands of pounds spent on infertility treatment.

We would also like to point out that $\mathrm{Mr}$ Pearce's advice on treatment for Neisseria gonorrhoea is inappropriate in these days of penicillinase producers and plasmid resistance. Ciprofloxacin or cefuroxime would be more appropriate. Antichlamydial treatment should start concurrently, not as a "two week follow up course," although two weeks' total treatment is essential. Doxycycline, however, would cover both organisms.

Ideally, if pelvic inflammatory disease is suspected it may be prudent to admit the patient to hospital through the department of genitourinary medicine for immediate and approriate antimicrobial tests and contact tracing. Tactful explanation to the patient about this detour is usually well accepted. If such a detour is not possible endocervical swabs for chlamydia and gonorrhoea must be taken and placed in the correct transport media before starting antibiotics, and the patient must be referred as soon as possible. One week and three weeks after admission the patien should return to the department for "tests of cure" and for further counselling. Contact tracing and subsequent treatment of patients' consorts may avert a second attack.

Liaison between gynaecologists and genitourinary physicians greatly enhances the patient's management and greatly reduces morbidity and cost. Why should patients suffer lifelong for a night's pleasure because doctors are reluctant to recognise coitus as the cause of pelvic inflammatory disease?

OLWEN E WILLIAM COLM O'MAHONY

Royal Liverpool Hospital

Liverpool L7 8XP

1 Pearce JM. Pelvic inflammatory disease. $\mathrm{Br}$ Med $\mathcal{F}$ 1990;300: 1090-1. (28 April.)

SIR,-Mr J M Pearce says in his editorial that swabs from the rectum and oropharynx rarely, if ever, add useful evidence to vaginal and urethral swabs.' I agree that cervical and urethral swabs give a high yield of positive results but suggest that rectal swabs should be taken because the recta mucosa is infected in $35-50 \%$ of women with gonococcal cervicitis. ${ }^{23}$

Most rectal infections occur without acknowledged rectal sexual contact. Because the prevalence of rectal infection in women is positively correlated with the duration of endocervical infection ${ }^{4}$ it would seem sensible to screen the rectum for infection when gonococcal pelvic inflammatory disease is suspected. If a sensitive explanation is given acrimony can be averted in most cases. Cervical swabs stained by Gram's method are negative in $40-60 \%$ of women with gonococca salpingitis and examination of rectal swabs by Gram staining may help, therefore, in early identification of the causative organism.

R J COKER

Department of Genitourinary Medicine,

St Mary's Hospital, London W 2 INY

1 Pearce JM. Pelvic inflammatory disease. Br Med $\mathcal{f}$ 1990;300. 1090-1. (28 April.)

1090-1. (28 April.)
Thin RN, Shaw EJ. Diagnosis of gonorrhoea in women. British Thin RN, Shaw EJ. Diagnosis of gonorrh

3 Barlow D, Phillips I. Gonorrhoea in women: Diagnostic, clinical and laboratory aspects. Lancet 1978;i:761.

4 Kinghorn GR, Rashid S. Prevalence of rectal and pharyngeal infection in women with gonorrhoea in Sheffield. British fournal of Venereal Diseases 1979;55:408.

\section{Screening and the 1990 contract}

SIR, - Dr D Slater's concern about the increased load on laboratory services generated by the new contract for general practitioners is pertinent'; there has already been a recent increase from three to four weeks in the reporting time for cervical cytology reports in this district. Dr Slater's estimate for the histopathology resources needed to service increased minor surgery in general practice may, however, be overgenerous. A large proportion of minor surgery will entail procedures such as soft tissue injections which do not use laboratory time.

In my practice, which serves a population of 1900 patients, 104 minor surgical procedures were performed in one year, of which 56 were soft tissue injections; of the remaining 48 , only 24 led to histopathological analysis.
Extrapolating these data to the 70 general practitioners expressing an interest in performing minor surgery in Rotherham, 1680 specimens for histopathology per year would be generated compared with Dr Slater's figure of 4000 . Also, much of the minor surgery would have been carried out previously in hospital, at higher cost. Thus the estimate of extra funding can be reduced further.

N E EARLY

Chesterfield S4O 0ER

1 Slater D. Screening and the 1990 contract. Br.Med f 1990;300 1074. (21 April.)

\section{Management of constipation}

SIR, - Professor $\mathrm{R}$ Taylor mentioned in his recent article that fibre supplements may be used to treat constipation in elderly people. ${ }^{1}$ Constipation is a common symptom in this age group,,$^{2}$ and in sick, immobile old people it is even more common, often accompanied by poor colonic motility and delayed transit times. ${ }^{3}$ In many geriatric units wheat bran is added routinely to the hospital diet.

We investigated the effects of adding $10 \mathrm{~g}$ of wheat bran to the diet of 20 elderly patients (mean age 77 ) who had been in hospital longer than one month and were bed bound. The study included a placebo phase (two weeks), a treatment phase (four weeks), and a second placebo phase (three weeks). Patients and nurses were told that fibre would be added to the diet to control constipation by natural means. This message was reinforced by written information. Menus were simplified to include soups, stews, and porridge to which finely milled bran could be added easily. During the placebo phases food was thickened but no bran was added.

Bran improved stool weight and consistency and reduced the number of days without stools, but faecal incontinence was a frequent and distressing side effect in 10 of 20 patients on bran compared to three on placebo $(\mathrm{p}<0.05)$. Placebo effects on symptoms were prominent in both patients and staff. An earlier study of younger subjects with irritable bowel syndrome also revealed powerful placebo effects. ${ }^{+}$

Frail elderly people may have lax anal sphincters that cannot retain soft or liquid faeces resulting

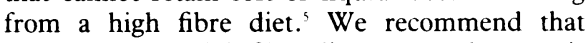
treatment with high fibre diets or supplements is avoided in this group of elderly people.

ME ARDRON A N H MAIN

University Department of Geriatric Medicine,

Selly Oak Hospital,

Birmingham B296jD

1 Taylor R. Management of constipation: high fibre diets work. Br Med f 1990;300:1063-4. (21 April.)

2 Thompson WG, Heaton KW. Functional bowel disorders in apparently healthy people. Gastroenterology 1980:79:283-8.

3 Brocklehurst JC, Kirkland JL, Martin J, Ashford J. Constipation in long stay elderly patients: its treatment and prevention by lactulose, poloxalkol-dihydroanthroquinolone and phosphate enemas. Gerontology 1983;29:181-4.

4 Lucey MR, Clark ML, Lowndes JO, Dawson AM. Is bran efficacious in the irritable bowel sundrome? A double blin placebo controlled crossover study. Gut 1987;28:221-5.

Barratt JA. Effect of wheat bran on stool size. Br Med $\mathcal{f}$ 1988;296:1127-8.

\section{Terminal care in general practice}

SIR,-Dr A C Blyth's audit of terminal care in a training practice noted that all recently bereaved families were visited for counselling' - I fear that such visits are not usually offered.

A study of over 300 recently widowed spouses showed that only $33 \%$ were visited at home by their general practitioners in the five to seven months after bereavement and $24 \%$ were not seen at all General practitioners' views about the need for 